\title{
IMPLEMENTATION OF BUSINESS INTELLIGENCE ON BANKING, RETAIL, AND EDUCATIONAL INDUSTRY
}

\author{
Arta M. Sundjaja \\ School of Information Systems, Bina Nusantara University \\ Jln. K. H. Syahdan No. 9, Jakarta 11480, Indonesia \\ asundjaja@binus.edu
}

\begin{abstract}
Information technology is useful to automate business process involving considerable data transaction in the daily basis. Currently, companies have to tackle large data transaction which is difficult to be handled manually. It is very difficult for a person to manually extract useful information from a large data set despite of the fact that the information may be useful in decision-making process. This article studied and explored the implementation of business intelligence in banking, retail, and educational industries. The article begins with the exposition of business intelligence role in the industries; is followed by an illustration of business intelligence in the industries and finalized with the implication of business intelligence implementation.
\end{abstract}

Keywords: Business Intelligence, Banking Industry, Educational Industry, Retail Industry

\section{INTRODUCTION}

Globalization era has changed people in the industrial world in managing their business. Various products are introduced to people from various segments to attract attention so that in the end they will use the products. The use of information technology in automating business processes in information system where a company will save transactional data in a large amount. The use of information technology allows companies to automate business process. In the big data era, companies have to manage large data transaction that is difficult for a human being to analyze directly and deduce useful information from the data [1].

Data mining can give contribution towards the solution of business problems in the industry by identifying the current pattern and trend, how the behavior of stage funds towards the condition of the economy, politics, and social. Correlation between various variables in business data cannot be directly seen by the managers since the volume of data is overly large. Managers require additional works to reach a conclusion regarding the behavioral pattern of the customers. Also, many additional works are required to comprehend, dissociate, preserve, and nurture favorable customers. Business intelligence and data mining help the managers and products' managers identify various classes of customers and develop compatible products or services with the customers' needs and or the act of determining pricing strategy to obtain better revenue management [2].

\section{METHOD}

Research studied and explored the implementation of business intelligence in banking, retail, and educational industries and its effects in increasing the decision-making process to solve the industry business problems. Article begins with an exposition regarding the role of business intelligence in each industry. It illustrates and discusses the implications of business intelligence.

\section{Literature Review}

\section{Definition of Business Intelligence}

Business intelligence is defined as a process of extracting, transforming, managing, and analyzing business data to support decision making process [3]. The process involves a set of data obtaining from a data warehouse. The process of business intelligence includes five stages:

Data sourcing; the system of business intelligence can extract data from various data sources and various business units such as marketing, production, human resources, and financial. The extracted data should be cleared, transformed, and integrated for analysis.

Data analysis; in this stage, the data are converted to information or knowledge through various analysis techniques such as, visualization and data mining. The result of the analysis process can help the management understand the situation and make a better decision. 
Situation awareness; the awareness towards situation can provide deeper comprehension in current situational decision based on the result of data analysis.

Risk assessment; the awareness towards sufficient various situations can help managers predict the future, identify threats and chances, and respond in accordance with needs. Nowadays, business operates in complex environmental condition. The decision making of business is more likely to be accompanied with risks that are coming from external and internal environments. Hence, it can be concluded that risk estimation is a main function in business intelligence system.

Decision support; the main purpose of business intelligence is to help managers in making decision wisely based on the current business data.

\section{The Architecture of the System of Business Intelligence}

Inmon divides the business intelligence system, as cited by [3], into four-level components and metadata management module. The general architecture of business intelligence system is shown in Fig. 1.

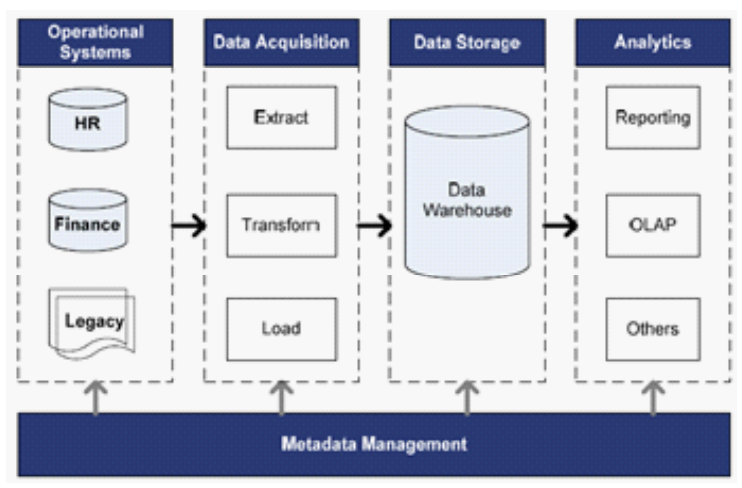

Fig. 1: Architectural Business Intelligence Systems in General [3]

The components in Fig. 1 interact with each other to facilitate the fundamental functions of business intelligence: extracting data from the operational system of the company, saving extracted data into data warehouse, and fetching the saved data for various applications of business analysis.

Level of operational system; as data sources from the system of business intelligence, business operational system typically uses the system of online transaction processing (OLTP) to support daily business activities.

Level of data acquisition; in this level, a component before the process is divided into three stages: extraction, transformation, and loading (ETL). A company has several systems of OLTP that bring out a very large number of data. The data first are extracted from OLTP's system of ETL's process and then transformed in accordance with transformation rules. If the data have been transformed, the data, then, are input in data warehouse. ETL is a basic component of business intelligence system because the quality of data from other components depends on the process of ETL. In the planning and developing of ETL, the quality of data, system flexibility, and speed process are the main concern.

Level of analytical; based on data warehouse, various types of analytical applications have been developed. The system of business intelligence supports 2 basic types in analytical function: reporting and online analytical processing (OLAP). The function of reporting provides managers various types of business reports such as sales report, products report, and human resources report. Report is produced from operating queries into data warehouse. Generally, data warehouse queries have been defined by data warehouse developer. Reports that have been made by business intelligence's system typically have static format and contain exact type of data.

Business intelligence analytical that is very promising is OLAP. According to Codd et al as quoted by [3], OLAP enables managers to go deeper into business data from multi-dimensional analysis through slice, dice, and drilling operations. A dimensional analysis is a perspective through how the data are presented, for instance: type of products, sales location, time, and customers. Compared to report function, OLAP supports data analysis in accordance with needs. OLAP is a model of multidimensional data known as star schema and snowflake schema. In addition to reporting and OLAP, there are a lot of other analytical types that can be made based on the system of data warehouse, such as data mining, executive dashboards, customer relationship management, and business performance management.

Metadata management; metadata is a distinctive data concerning other data, such as data sources, data warehouse saving, business regulations, access authorization, and how data is extracted and transformed. Metadata is very important in producing accurate and consistent information and system maintenance. The management of metadata influences all process from plan, develop, test, deployment and the use of business intelligence system.

\section{Business Intelligence in Banking Industry}

The implementation of business intelligence in banking industry is the key success in making the main business activities effective and efficient. It has the ability in obtaining, managing, and analyzing the data of customers, products, services, operational activities, suppliers, and partnerships in a very large numbers. Examples of the implementation in business intelligence in banking industry are 
customer relationship management, customer credit analysis, risk management, credit card analysis, customer segmentation, etc. [4,5].

The role of business intelligence in business activities can provide more personal services towards customers and radically increases the service quality from the bank. Banking product managers compete in designing products and services that can answer every need in certain segment.

One example of the use of customer credit analysis is the implementation of consumer credit scoring [6]. Consumer credit scoring is the most important activity to evaluate consumer loan application. The credit scoring system is used to model the risk potential from loan application, where the system has benefits for swiftly handling numerous loan applications without requiring a lot of resources so that it can reduce operational cost and reduce reasoning in decision making effectively. With the competition and growth of consumer credit market, players in banking industry compete each other to develop improved strategy with the help of the implementation of customer credit scoring model.

The purpose of credit scoring is to contribute competence to the part of credit analysis to decide the consumer loan application that has been accepted by the marketing of the bank including a "good credit" where customers included in the category have significant possibility to pay their financial responsibility towards the bank; or a "bad credit" where costumers included in the category have significant possibility to fulfill their financial responsibility.

Results of study conducted by Ref. [6], researchers compared the performance of credit scoring models using the traditional approach and artificial intelligence (discriminant analysis, logistic regression, neural networks, classification, and regression tree). Experimental research with real data has demonstrated that classification, regression tree, and neutral networks overpower the performance of credit scoring model traditionally in terms of prediction accuracy and type II errors. Analysis towards customer data is the key point for the management of the bank to afford maximal revenue. By using pareto concept, designing products and services towards $20 \%$ of customers can provide the results of $80 \%$ for the profits. The management believes that by analyzing $20 \%$ of the customers is an effective step to increase profit and decrease operational cost. In addition to the above case, the management of the bank may analyze card marketing, selling price calculation, and the rate of profit to card owner, the potential for fraud detection, and prediction of customer lifecycle management.

Customer segmentation is an effective marketing strategy, by comprehending the characteristics and needs of every customer segment; then the management may design how to market the price, policy for every product and service in order to provide maximum benefit [7]. The implementation of business intelligence in customer segmentation, the process becomes easier because management can easily identify customers' demographic and geographic. Nevertheless, the management has to spare some time and energy if it wants to know about customers' psychographic and behavior. In addition, the management has to identify necessary attributes, such as ages, occupations, incomes, and genders. The attributes easily and commonly can be measured with RFV (recency, frequency, and value from their transactional behaviors) $[8,9]$.

It can be concluded that fulfilling the needs of customers becoming more complex and the efficiency of business processes with automation, operational activities need supports in system information. System information in banking should still be developed in order to meet the needs of customers and follow business innovation. However, it should be integrated into business intelligence system so that the management obtains up-to-date information and insight from historical data.

\section{Business Intelligence in Retail Industry}

Observing the growth of retail industry in Indonesia, customer relationship management (CRM) is a primary trigger in perceptive businessmen to redesign the focus of their business toward the customers. Retail companies generally have a lot of customers; and the customers commonly have different needs. With the implementation of CRM, then, the management can automate interaction between customers and sales team. It can analyze customers' data obtained from POS transaction, customer service, etc. so that the management may acquire insight towards the customer needs and develop oneto-one relationship with the customers, design and promotional campaign, product layout optimization. Analytical CRM uses business intelligence tools, such as data warehousing, data mining, and OLAP. Some applications of analytical CRM are customer segmentation, campaign/promotion effectiveness analysis, customer lifetime value, customer loyalty analysis, cross selling, product pricing, and target marketing [4].

Some retail companies start to persuade buyers who have not become their member to issue their member card, collaborate with the bank to provide discount, etc. The management starts to realize the importance to obtain comprehensive customer data, where the data can give information such as customer characteristic (age, gender, marital status, education, occupation, income per month), customer behavior (customer feedback related to products and services, recommendation from customers related to products and services, substitution products used by customers, 
customers loyalty toward services from certain brand of a product), and customer expense (purchase price, quantity, frequency of repeat purchases, customers' desire to buy other products and services from a particular manufacturer, etc.) [10]. According to customer's segmentation performed by Ref. [10], it can be concluded as follows.

Category 1 is customers who work at office as professional and manager, have a fairly high education, and have house and car. Based on the information obtained, the customers from this category do not have baby, yearly income is not so high but they love shopping especially in fashion. The focus of consumption in this category is high quality cosmetics, original CDs, magazines, and house ware products in general. Generally, they are not interested in getting food and beverages since their incomes are considerably high. The compatible marketing strategy in this category is to provide higher quality of products and services in order to attract customers because customers from this category are not really interested in discounts.

Category 2 is customers who work in factory as worker and mechanic; and relatively have low income. Some of them have house; shop for food, domestic purposes and toddler' products. Most of them are women who like to go to supermarket to buy more stuff. In general, they are interested in promotional discounts, so that the revenue is not really high.

Category 3 is customers who have low education, low income that almost the same with factory worker. In general, they buy more commodities when there is a substantial discount. Marketing strategy for this category is to provide promotional discount towards the commodities so that it attracts more customers.

Table 1. Examples of some types of customer segmentation supermarket in China

\begin{tabular}{|c|c|c|c|}
\hline variable & Cluster-1 & Cluster-2 & Cluster-3 \\
\hline Membership Card & $\begin{array}{c}\text { Gold Silver } \\
\text { Copper Cards }\end{array}$ & $\begin{array}{c}\text { Gold } \\
\text { Copper Cards }\end{array}$ & $\begin{array}{l}\text { Com mon } \\
\text { Cards }\end{array}$ \\
\hline Level of education & $\begin{array}{l}\text { Bachelor } \\
\text { Master }\end{array}$ & $\begin{array}{l}\text { College High } \\
\text { School }\end{array}$ & School \\
\hline Caste & $\begin{array}{l}\text { Professional } \\
\text { Manager }\end{array}$ & $\begin{array}{c}\text { Worker } \\
\text { Mechanic }\end{array}$ & $\begin{array}{l}\text { Worker } \\
\text { Mechanic }\end{array}$ \\
\hline $\begin{array}{l}\text { The number of } \\
\text { cars }\end{array}$ & $2-3$ & $1-2$ & $1-2$ \\
\hline Fixed address & have & have & Have(less) \\
\hline Annual income & $\$ 50 \mathrm{~K}-90 \mathrm{~K}$ & $\$ 30 \mathrm{~K}-50 \mathrm{~K}$ & $\$ 10 \mathrm{~K}-30 \mathrm{~K}$ \\
\hline Proportion & $44.33 \%$ & $37.09 \%$ & $18.58 \%$ \\
\hline
\end{tabular}

The implementation of business intelligence within the area of CRM, BI can be applied to supply chain management (SCM). By applying the SCM, the management of the company can efficiently control the inventory and purchasing process to the suppliers. The data taken from purchasing process and supply may contribute various competitive insights for dynamical supply chain. The implementation of data warehouse to SCM can help the management in analyzing suppliers' performance and controlling stock level (safety stock, lot size, and lead time analysis), product movement, demand forecasting, etc.

The implementation of BI in alternative sales channel can increase the effectivity in managing various types of distribution channels such as Internet, catalog, etc. With the development of today's technology, it enables a customer to interact with the company through various channels in a period. As an example, the development of tablet and smartphone causes the management to expand m-channel to provide additional choices for customers to access the company. The application of BI in alternative sales channel is E-business analysis, web log analysis, referrer analysis, error analysis, keyword analysis, web hosting, channel profitability, and productchannel affinity.

\section{Business Intelligence in Educational Industry}

Nowadays the implementation of business intelligence in educational industry is relatively lower than banking industry, health, insurance, etc. [11]. The implementation of business intelligence in educational industry can be done in the process of college admission, teaching management, etc. $[12,13]$. According to Ref. [12], the competition for college admission is getting tougher every year with most college students receive the application of admissions and more selective in its acceptance. The level of acceptance in well-known university reaches $10 \%$; and the uncertainty causes talented students apply to the school on the next layer. This causes students to insert application to several different schools and every school has different due date. As an effect, students often face with dilemma when they are running out of time to accept the offer from a university that is lower than their priority.

The challenge in the admission process is process of identifying the best applicant including some parameter and when the desired candidate is identified, then the decision to propose an offer and the composition of the offer is moderately hard. In addition to the process of students' admission, the application of data mining can be used to support teaching management. Every university manages students' mark in a very large number from different faculties. With the application of data warehouse and analyzing the data with various data mining techniques, the faculty manager can exploit different hidden information and perform forecasting and analysis. So that, faculty managers can use it to improve the quality of teaching and knowledge. 
Reference [12] was very sure that data mining and the technique of income management can be used effectively to solve the problem. Data mining is used to expand the model that can predict the quality of applicants using student performance data based on past performance of the students in the first year in terms of GPA and some important parameters gathered from the applicants' data, such as: high school GPA, SAT math score, SAT verbal score, strength of curriculum, adjusted GPA, adjusted test scores, subjective score, and overall assessment score.

This research used neutral networks method since it has better performance compared to decision trees, besides that the capability of neural networks in adapting with situational modification makes this method compatible with the context of college admissions. The model of income management is already widely used by companies in the airline industry and the hotel. This technique maximizes revenue by collecting the best price for each bench/ resource despite of the uncertainty about future demand. This research used dynamical model that is markovian periods since it has capability to handle demands which come randomly. The table of offered price can be used as a reference for the admission staffs to accept or decline application from the students' candidate.

Table 2 provides assumption of the total accepted applicants in every week for three categories within 4 weeks, the total of the applicants including the applicants that are accepted and rejected. Table 3 shows offered price for a time period with additional 4000 , every 4000 accumulation in a period of approximately 3.3 days.

Table 2 Total of accepted applicants in every week [12]

\begin{tabular}{lcccc}
\hline & \multicolumn{4}{c}{ Number of Applicants } \\
\cline { 2 - 5 } & Week 1 & Week 2 & Week 3 & Week 4 \\
\hline Low Tier & 1200 & 1000 & 1200 & 1100 \\
Middle Tier & 300 & 300 & 350 & 350 \\
High Tier & 200 & 200 & 150 & 250 \\
\hline
\end{tabular}

Table 3 Offered price [12]

\begin{tabular}{|c|c|c|c|c|c|c|c|c|c|}
\hline & \multicolumn{9}{|c|}{ <- Markovian Time Period -> } \\
\hline & Seats & P2000 & P6000 & P10000 & P14000 & P22000 & P26000 & P30000 & End \\
\hline \multirow{10}{*}{ 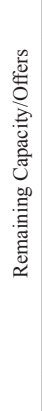 } & 100 & 3.75 & 3.75 & 3.75 & 3.75 & 3.75 & 3.75 & 3.75 & 2.57 \\
\hline & 200 & 3.75 & 3.75 & 3.75 & 3.75 & 3.75 & 3.75 & 3.25 & 2.50 \\
\hline & 300 & 3.75 & 3.75 & 3.75 & 3.75 & 3.73 & 3.25 & 3.25 & 0.00 \\
\hline & 400 & 3.75 & 3.75 & 3.75 & 3.75 & 3.25 & 3.25 & 2.54 & 0.00 \\
\hline & 500 & 3.75 & 3.75 & 3.75 & 3.60 & 3.25 & 3.25 & 2.50 & 0.00 \\
\hline & 600 & 3.75 & 3.75 & 3.65 & 3.25 & 3.25 & 3.25 & 2.50 & 0.00 \\
\hline & 700 & 3.75 & 3.70 & 3.25 & 3.25 & 3.25 & 2.51 & 2.50 & 0.00 \\
\hline & 800 & 3.73 & 3.25 & 3.25 & 3.25 & 3.25 & 2.50 & 2.50 & 0.00 \\
\hline & 900 & 3.27 & 3.25 & 3.25 & 3.25 & 2.68 & 2.50 & 2.50 & 0.00 \\
\hline & 1000 & 3.25 & 3.25 & 3.25 & 3.25 & 2.50 & 2.50 & 2.40 & 0.00 \\
\hline
\end{tabular}

By using the above approach, the university can directly make decision to all students enrollment and on the same time maximize the process of enrollment by accepting the best student with the offered capacity. Reference [13] analyzed students' marks from several courses of industrial enterprise electrification within a university to find out the connection of the marks and several different courses through decision tree technique. Table 4 is a database from the students' scores which contain student serial numbers and the result of some several major courses (fundamental of electrical engineering-FEE, electrical machine and drive-EMD, automatic control principle-ACP, automatic control system-ACS, and higher mathematic-HM).

Table 4 Students' Scores [13]

\begin{tabular}{cccccc}
\hline ONS & HM & EMD & ACP. & ACS. & FEE. \\
\hline 1 & 80 & 75 & 65 & 70 & 68 \\
2 & 74 & 67 & 62 & 74 & 65 \\
3 & 78 & 81 & 54 & 63 & 62 \\
4 & 65 & 68 & 58 & 65 & 68 \\
5 & 88 & 82 & 78 & 80 & 82 \\
6 & 91 & 85 & 80 & 83 & 85 \\
7 & 85 & 82 & 78 & 84 & 78 \\
$\ldots$. & $\ldots$. & $\ldots$. & $\ldots \ldots$ & $\ldots \ldots$ & $\ldots$ \\
210 & 78 & 72 & 56 & 62 & 64 \\
& & & & & \\
\hline
\end{tabular}

To facilitate in data mining usage, the data from Table 4 should be transformed in conditions as follows. (1) If the value is below 60 then fill it with 0 (not pass) and if the value is above 60 then fill it with 1 (pass) by using the decision tree algorithm C4.5. (2) If the value of course FEE (A) passes, then the value of course ACS (C1) generally will pass. The accuracy rate is $86.4 \%$ and the covering rate for students is $59.5 \%$. (3) If the value of course FEE (A) fails, and the value of course EMD (B) also fails, then the value of course ACS (C1) typically fails. The accuracy rate is $85.7 \%$ and the covering rate for the total of students is $10 \%$. (4) If the value of course FEE (A) fails, but the value of EMD (B) passes, then the value of ACS (C1) can still pass. The accuracy rate is $81.25 \%$ and the covering rate for the total of students is $30.5 \%$.

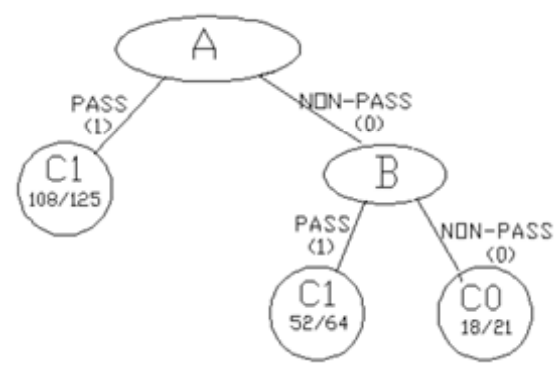

Fig. 2: Decision tree to evaluate students' scores [13] 
With the above approach in evaluating students' scores, then the faculty manager can notice the connection between the students' performance toward the courses of FEE, ACS, and EMD. Based on the result of the evaluation that has been made, EMD course's instructor needs to give more attention to the students who did not pass EMD and ACS.

\section{CONCLUSION}

Managements of various industries have to develop information system to fulfill the complex stakeholder's needs. In order to use the information obtained from business activity through the information system, it is necessary to develop business intelligence system. In addition, by integrating the obtained insight from historical data, the system of business intelligence may enable the management to anticipate future behavior from the system and allows the modeling of customer behavior. The characteristic of the implementation of business intelligence system is to support the quality and to prompt decision making.

\section{REFERENCES}

[1] P. Trkman, et al., "The impact of business analytics on supply chain performance," Decision Support System, 49(3), pp. 318-327, 2010.

[2] B. Ubiparipović and E. Đurković, "Application of Business Intelligence in the Banking Industry," Management Information System, 6(4), pp. 23-30, 2011.

[3] L. Niu, J. Lu, and G. Zhang, Cognition-Driven Decision Support for Business Intelligence, German: Springer-Verlag Gmbh, 2009.

[4] J. F. Hair, "Knowledge creation in marketing: the role of predictive analytics," European Business Review, 19(4), pp. 303-315, 2007.

[5] Z. Dan, "Data mining application in the banking industry in China (1997-2007), in International Conference on Information Management, Innovation Managementand IndustrialEngineering, pp. 240-243, 2008.

[6] H. Ince \& B. Aktan, "A comparison of data mining techniques for credit scoring in banking: a managerial perspective," Journal of Business Economics and Management, 10(3), pp. 233-240, March 2009

[7] M. A. Mawoli \& D. Abdulsalam, "Effectiveness market segmentation and viability of islamic banking in Nigeria," Australian Journal of Business and Management Research, 1(10), pp. 1-9, Jan. 2012.

[8] S. Sun, "An analysis on the conditions and methods of market segmentation," International Journal of Business and Management, 4(2), pp. 63-70, Feb. 2009.

[9] Z. Lin, et al, "Banking intelligence: application of datawarehouse in banking operation," in Service Operation and Informatics. pp. 143-146, 2008.
[10] S. Zhou \& G. Lei, "Application of data mining technology in membership supermarket's customer segmentation." in International Conference on Business Computing and Global Informatization, pp. 181-183, July 2011.

[11] S. Lihua, Z. Yongsheng, \& Z. Zhonglei, "Research on data mining in college education," in International Conference on Computer Science and Software Engineering, 5, pp. 385-388, Dec. 2008.

[12] S. Rebbapragada, A. Basu, \& J. Semple, "Data mining and revenue management methodologies in college admissions," Communication of the ACM, 53(4), pp. 128-133, April 2010.

[13] Z. Liu \& X. Zhang, "Prediction and analysis for students' marks based on decision tree algorithm, in 3rd International Conference on Intelligent Networks and Intelligent Systems, pp. 338-341, 2010. 